\title{
COVID-19 and Biomedical Publishing: Challenges and Prospects
}

\author{
Muhammed Mubarak \\ Department of Histopathology, Sindh Institute of Urology and Transplantation (SIUT), Karachi, Pakistan
}

The currently prevalent pandemic of novel coronavirus infectious disease 2019 (COVID-19), which originated from Wuhan, China, in December 2019, has spread very fast and profoundly affected all spheres of human life all over the world in an unprecedented manner. ${ }^{1}$ It is caused by a novel coronavirus named severe acute respiratory syndrome coronavirus 2 (SARS-CoV-2), which was most probably transmitted from bats to humans. ${ }^{2}$ Subsequent human-to-human spread of the infection was so fast that it resulted in the prevailing global pandemic in just few months' time. No part of the planet Earth is spared from the disease. The disease primarily affects the upper respiratory tract, but as the number of cases and experience with the disease grows, it has become evident that it can involve almost all parts/systems of the body, either directly or indirectly. 3,4

The global response to COVID-19 was equally of an unparalleled scale and was partly drawn from the lessons learned during some other disease epidemics in the recent decades. The scientific community responded to this deadly threat to human health in an equally overzealous manner. The amount of research, both basic and applied, being carried out on COVID-19 disease, has no precedent in the human history. The scope of research continues to be broad but is focused on diagnostics, and development of vaccines and effective drugs for the treatment of affected patients. The quick dissemination of the research findings was a big challenge for biomedical publishing industry and journals in the face of lockdowns, shutdowns and closure of almost all activities of human life..$^{5-9}$ COVID-19 pandemic has strained and reshaped the system of scholarly publishing in more than one ways, which was already changed in digital era. Leading international journals published by commercial publishers or big research communities, which had ample resources and staff, quickly responded to this challenge and adopted their working style accordingly.

Correspondence to: Prof. Dr. Muhammad Mubarak, Department of Histopathology, Sindh Institute of Urology and Transplantation, Karachi-74200, Pakistan

E-mail: drmubaraksiut@yahoo.com

Received: October 15, 2020; Revised: October 20, 2020;

Accepted: October 22, 2020

DOI: https://doi.org/10.29271/jcpsp.2020.JCPSPCR.CR92
COVID-19 has also changed the paradigm of publishing industry. Leading international journals are supporting this paradigm by encouraging authors to publish. They are doing so by expedited peer review process, waiver of author processing changes (APCs), and making the publications fully open access on COVID-19. In fact, the journals are now actively seeking research on COVID-19 to publish quickly and open access. Many journals, particularly the aforementioned international journals, expedited the publication process for COVID-19 articles with median time from receipt to acceptance of 6 days for journal articles. As a result, the volume of research published in recent pandemic has no parallels in the past. Other journals, mostly from developing countries, with limited staff and resources, were affected in a different way. Their publication process was delayed or stopped for some time. Many of these journals were not prepared to cope with such a devastating crisis. Their editors faced many problems and challenges in even publishing regular issues on time..$^{7-9}$ Categorisation of the submissions on COVID-19 was a challenge for the editors; as in many cases, the authors did not like to agree with the editors' decisions. In fact, almost every medical professional who has interest in medical writing is inclined these days to write a narrative review or short communication on COVID-19; and medical journals are getting innumerable requests to process them which, of course, is not feasible in many instances. This is mostly due to the fact that the regulatory bodies of different countries give different weightage to different categories of manuscripts; and authors wish to publish theirarticles in high-weightage category by any means.

Although the nature of this global public health crisis warrants expedited publishing, precautions are needed to protect the integrity of scientific evidence. The rapid dissemination of information has underscored some issues with communication of scientific results and conclusions in this time of heightened sensitivity and global apprehension. It is important to ensure that the scientific community is not an inadvertent source of misinformation and infodemic. This will require a multimodal approach, with support of all stakeholders including editors, publishers, preprint servers, authors and journalists. The paradigm of medical publications has changed, and a concerted approach is required to maintain a high standard of scientific communications..$^{7-9}$

Journal of College of Physicians and Surgeons Pakistan (JCPSP) was one of the first few Pakistani biomedical journals which responded to this crisis by publishing a special supplement (sup- 
plement I) on COVID-19. It included a large number (31) and variety of articles including Case Reports, Review Articles, Systemic Reviews, Meta-analysis, Commentaries, and Letters to Editor. ${ }^{10}$

This is the second supplement of JCPSP on COVID-19. This issue also includes 20 articles belonging to different categories on different aspects of COVID-19 disease. These include 10 Letters to Editor, 2 Short Communications, 2 Commentaries, 1 Clinical Practice Article, 1 Systematic Review, 1 Short Article, 2 Case Reports, and 1 Update Article. We have strived hard to convey authentic information to the healthcare community quickly, and hope the readers will find it useful.

\section{REFERENCES}

1. Chan JF, Yuan S, Kok KH, To KK, Chu H, Yang J, et al. A familial cluster of pneumonia associated with the 2019 novel coronavirus indicating person-to-person transmission: a study of a family cluster. Lancet 2020; 395(10223): 514-23. doi: 10.1016/S0140-6736(20)30154-9.

2. Lu R, Zhao X, Li J, Niu P, Yang B, Wu H, et al. Genomic characterization and epidemiology of 2019 novel coronavirus: implications for virus origins and receptor binding. Lancet 2020; 395(10224):565-74. doi: 10.1016/ S0140-6736(20)30251-8.

3. Mubarak M, Nasri H. COVID-19 nephropathy; an emerging condition encountered by novel coronavirus infection. J
Nephropathol 2020; 9(3):e21. doi: 10.34172/jnp.2020.21.

4. Asgharpour M, Zare E, Mubarak M, Alirezaei A. COVID-19 and Kidney Disease: Update on Epidemiology, Clinical Manifestations, Pathophysiology and Management. J Coll Physicians Surg Pak 2020; 30(Supp1):S19-S25. doi: 10.29271/jcpsp.2020.Supp1.S19.

5. Miller RC, Tsai CJ. Scholarly Publishing in the Wake of COVID-19. Int J Radiat Oncol Biol Phys 2020; 108(2): 491-5. doi: 10.1016/j.jirobp.2020.06.048.

6. Eisen MB, Akhmanova A, Behrens TE, Weigel D. Publishing in the time of COVID-19. Elife 2020; 9:e57162. doi: 10.7554/eLife.57162.

7. Jawaid SA, Jawaid M. Challenges faced by the Medical Editors in Post COVID19 Pandemic era. Pak J Med Sci 2020; 36(5):855-6. doi: 10.12669/pjms.36.5.3009.

8. Panda S. Publishing in the time of pandemic: Editorial policy of a dermatology journal during COVID-19. Indian J Dermatol Venereol Leprol 2020; 86:337-40. doi: 10.4103/ ijdvl.IJDVL_704_20.

9. Gupta L, Gasparyan AY, Misra DP, Agarwal V, Zimba O, Yessirkepov M. Information and Misinformation on COVID-19: A cross-sectional survey study. J Korean Med Sci. 2020; 35(27):e256. doi: 10.3346/jkms.2020.35.e256. doi: 10.3346/jkms.2020.35.e256.

10. Special Supplement 1 on COVID-19 | Volume 30 | Year 2020. J Coll Physicians Surg Pak. Available from:http:// jcpsp.pk/archive-detail.php 